\title{
Letramento crítico no ensino de língua inglesa: uma ferramenta de poder emancipatória
}

Critical literacy in English language education: an emancipatory power tool

Recebido em: 07/10/2019
Aprovado em: 09/12/2019
Publicado em: 19/12/2019

Fabiene de Oliveira Santos ${ }^{1}$

\begin{abstract}
RESUMO: Este trabalho busca refletir sobre as contribuições que a relação entre o letramento crítico e o processo de ensino e aprendizagem de língua inglesa, apoiada no diálogo com os estudos culturais sob a ótica do pensamento decolonial, podem possibilitar em prol de uma emancipação e de relações de poder e interculturais mais horizontais. Defende o letramento crítico no ensino de língua inglesa pautado nos estudos emergentes decoloniais, a fim de desenvolver no aluno a criticidade e favorecer a formação na língua inglesa como língua estrangeira na esteira da ideologia pela e para a ética, a justiça e o respeito. Inicialmente, apresenta considerações a respeito de letramento, destacando o letramento crítico na vertente do letramento ideológico. Em seguida, tece uma discussão sobre contribuições do letramento crítico no ensino de língua inglesa, à luz de estudos acerca da decolonialidade, realizados por pesquisadores do campo. Concluindo, a articulação proposta pode possibilitar um processo educacional que privilegie a consciência crítica e a reflexividade. O estudo sugere que o processo de ensino-aprendizagem de língua inglesa, mediante o letramento crítico, através de uma prática de ensino com o dissenso e do desenvolvimento de uma tradução híbrida-relacional-empática, comunga com uma formação para a língua ética, democrática, emancipatória.
\end{abstract}

Palavras-chave: Letramento crítico; Língua Inglesa; Decolonialidade.

ABSTRACT: This paper seeks to reflect on the contributions that the relationship between critical literacy and the English language teaching and learning process, supported by the dialogue with cultural studies from the perspective of decolonial thinking, can enable for the sake of emancipation and more horizontal and intercultural power relations. It defends the critical literacy in the teaching of English language based on the emerging decolonial studies, in order to develop in the student the criticality and to favor the formation in the English language as a foreign language in the wake of the ideology for and for the ethics, the justice and the respect. Initially, it presents considerations regarding literacy, highlighting the critical literacy in the ideological literacy aspect. It then discusses the contributions of critical literacy to English language teaching in the light of studies on decoloniality by field researchers. In conclusion, the proposed articulation can enable an educational process that favors critical awareness and reflexivity. The study suggests that the English language teaching and learning process through critical literacy, through a teaching practice with dissent and the development of a hybrid-relational-empathic translation, communes with a training for the ethical, democratic and emancipatory language.

Keywords: Critical Literacy; English Language; Decoloniality.

1. Graduação em Licenciatura Plena em Letras. Licenciatura em Pedagogia. Graduação em Odontologia. Especialização em Informática na Educação. Especialização em Docência na Educação Superior. Mestrado em Estudos Linguísticos. Doutoranda do Programa de Pós-Graduação em Estudos Linguísticos pela Universidade Federal de Uberlândia. ORCID: 0000-0001-9667-5149 E-mail: fabienedeoliveira@hotmail.com 


\section{INTRODUÇÃO}

O cenário mundial desafia o discurso educativo que apregoa a necessidade de formar cidadãos críticos e ativos na sociedade. Nós vivemos nos dias atuais em um mundo complexo, globalizado, repleto de informações e de relações sociais, culturais e econômicas apinhadas de desigualdades e de disputa por poder e domínio. Estamos imersos em uma cultura arraigada em valores que privilegiam o poder e os que detêm reservas monetárias como efeito do capitalismo e da colonialidade.

Para refletirmos e desafiarmos a lógica operante da colonialidade, tomada aqui como Mignolo (2005, p. 34-36) abarca, o outro lado da modernidade, e traz à tona a questão do imaginário de uma hegemonia, a fim de não silenciar a diferença colonial na modernidade, alvitramos o letramento crítico no ensino de língua inglesa como língua estrangeira, apoiado aos estudos decoloniais para expandirmos a visão de mundo binário, dividido em "superiores ideais" e "demais subordinados" e autônomo, automatizado para e nas desigualdades. Pensamos nas relações de força que se perpetuam na colonialidade, que ademais de não se desprenderem da colonização, alastram-se e asseveram a supremacia do eurocentrismo, da dominância de determinados países, como os que estariam no grupo superior, os considerados pelo termo naturalizado de "primeiro mundo", sobre outros, como o nosso país, veiculado como "terceiro mundo", que se encontraria no outro grupo, o debaixo/inferior.

O que vemos é que estamos em um mundo fatiado por desigualdades de naturezas sociais diversas e por diferenças de raça, gênero, em um mundo seccionado para os que se julgam "a raça, o intelecto e a língua superior". Mundo caracterizado pelo pensamento abissal, segundo concebe Santos (2009, p. 23-24), que, por um mecanismo regulador invisível e camuflado pela ordem contrária ao discurso da globalização, dificulta a colaboração entre os povos, o diálogo socioeconômico e cultural. É nesse universo abissal que circulam discursos como o da globalização com efeito de sentido de englobar ou silenciar o local em uma aldeia global, o discurso do utilitarismo da língua inglesa como totalitária, língua inglesa como a língua franca, universal e unificadora das nações. Discursos esses que capturam os sujeitos de modo a buscar a identidade inglesa, identidade entendida em conformidade com Hall (2008, p. 108), como um conceito posicional, identidade que não é fixa e nem singular, pois é produzida historicamente em meio a jogos de poder, exigindo habilidades de fluência e domínio da língua como se 
fosse um nativo ${ }^{1}$ da cultura inglesa para estar, ou seja, posicionar-se nesse "mundo", ocidental. E é na lógica desse mundo de embate de forças, de grande circulação de informações, (des)conexões, estratégias capitalistas, manipulações pela produção de um ideal, um padrão europeu, que o aluno se (de)forma e que habilidade(s) se impõe(m). Isto é, uma habilidade é ditada pela cultura dominante, impondo ao outro lado da modernidade a necessidade de múltiplas habilidades para resistir e tecer um diálogo intercultural.

Logo, ensejamos a proposta de ensino de língua inglesa a partir do letramento crítico, pelo viés sociocultural e ideológico ${ }^{2}$, aliado aos estudos culturais, à decolonialidade, que concorre para o desenvolvimento da criticidade no aluno, da percepção do (in)visível e (in)dizível do horizonte, mediante o processo de ensino-aprendizagem com e para a ética, a escuta do outro, como sinalizam Freire (2002, p.43-44) e Souza (2011a), para dialogar na língua, a responsabilidade com a língua.

Iniciamos este trabalho com considerações a respeito de letramento, focalizando o letramento crítico pelo viés do modelo ideológico, em oposição ao modelo autônomo, como define Street (2013, p. 53). Na sequência, buscamos empreender uma discussão sobre as contribuições do letramento crítico para o ensino e a aprendizagem da língua inglesa como língua estrangeira, na vertente dos estudos culturais da pós-modernidade. Vale ressaltar que nosso objetivo não é imprimir uma metodologia de ensino, mas esperamos contribuir com reflexões teóricas para o campo da Linguística Aplicada pela relevância social do tema no cenário atual.

\section{Considerações sobre letramento para o ensino de língua inglesa}

Há um crescente debate acerca da noção de letramento. Dentre autores que discutem o tema, Goulart (2014, p. 37-39) toma o conceito de letramento "como uma estratégia de compensação". E aduz sobre a natureza do termo letramento, a partir de uma retrospectiva sobre a educação escolar brasileira, considerando que, da mesma forma como foram desenvolvidas estratégias políticas para compensar e contornar problemas sociais, o letramento no Brasil teria a mesma natureza estrategista de "resposta" a essas questões sociais: compensatória. Nesse sentido, o termo carrega a conotação de déficit, ou seja, vem para suprir um problema social, uma defasagem no processo de leitura e

\footnotetext{
1 Termo que, apesar de comum entre professores e alunos de língua inglesa, gera debates. Sugerimos ver Jordão e Martinez (2015).

2 Em relação ao modelo de letramento proposto por Street (2013).
} 
escrita. O cerne do termo assim se relaciona com o discurso naturalizado no país da "falta", uma falta que se encontra na memória coletiva e que também é dada à impossibilidade histórica do dizer/fazer e das relações de poder desiguais que se perpetuam na atualidade (a questões de colonização e colonialidade). No ensino de língua inglesa, como podemos observar, tornaram-se recorrente os discursos da "dificuldade" e da "falta", para a aprendizagem, principalmente, ligados à oralidade. Esses sentimentos de falta e dificuldade que ecoam pela língua condizem com o regime da colonialidade, com um ensino envolto pela cultura eurocêntrica que privilegia o grafocentrismo, ou seja, uma sociedade que toma o registro, a escrita como o modo de interação mais operante, o que determina e firma as relações sócio-históricas. Além de focar o ensino em regras descontextualizadas, perdurando a tradição da língua soberana. Um ensino na visão da origem europeia, o modelo ocidental, e que trata o sujeito no processo de aprendizagem para permanecer operando a língua como uma decodificação direta, a língua como código, que não privilegia o engajamento na vida sociopolítica e, menos ainda, na e para a sociopolítica da vida - esfera que se relacionaria ao letramento crítico.

A questão da (im)pertinência do conceito de letramento relaciona-se à participação dos sujeitos nas esferas superiores de enunciação, extrapolando a trivial participação em práticas sociais de leitura e escrita. Esta participação deve envolver um sentido de liberdade e de autonomia que possibilitaria aos sujeitos a sua sucessiva integração e aprofundamento na vida social, tornando-os mais livres e criativos para reinventar continuamente gêneros e linguagens sociais. (GOULART, 2014, p. 47-48).

É nessa direção que o ensino de língua inglesa pode fomentar a mobilidade e o diálogo cultural, não como mera imposição curricular por demanda por uma língua universal, com um ensino fixado em regras invariáveis e repetições mecânicas, sob uma educação autônoma - relacionando com o modelo autônomo de letramento proposto por Street (2013), mas um processo de ensino e aprendizagem sobre as múltiplas e históricas regras que variam nos contextos, uma noção de língua que não é neutra, e que carrega a ideologia para a tomada de posição do sujeito aprendente. Esse é o letramento que pensamos para o ensino de língua inglesa, o letramento crítico que é pertinente como ferramenta de reflexão e proposição de questões para a participação na vida social.

Neste estudo, nos apoiaremos, principalmente, nos fundamentos postos por Street $(2013,2012)$ ao abordar um modelo de letramento ideológico. Consoante a Street, os 
Estudos dos Novos Letramentos (New Literacy Studies - NLS) não focam tanto na aquisição de habilidades, mas no que significa assumir o letramento como prática social. Os novos letramentos,

não tomam nada como certo em relação ao letramento e às práticas sociais aos quais se torna associado, problematizando o que conta como letramento em dado tempo e lugar e questionando "de quem" são os letramentos dominantes e "de quem" são os letramentos marginalizados ou que resistem. [...] A pesquisa em NLS [...] sugere que, na prática, o letramento varia de um contexto para outro e de uma cultura para outra e, assim, consequentemente, variam os efeitos dos diferentes letramentos em diferentes condições. A abordagem autônoma simplesmente impõe concepções particulares, dominantes de letramento a outras classes sociais, grupos e culturas. O modelo alternativo, ideológico, de letramento oferece uma visão culturalmente mais sensível das práticas de letramento, pois elas variam de um contexto para outro (STREET, 2013, p. 53).

O autor se refere a um modelo de letramento alternativo, ideológico, em que, além de postular o letramento como uma prática social e não simplesmente uma habilidade técnica e neutra, nessa abordagem, percebe-se que o letramento varia de um contexto a outro. Tal modelo é pensado em oposição ao modelo autônomo de letramento. Sobre o modelo autônomo, Street (2013, p. 51) explica que se trata de "uma abordagem universal, independente da cultura, baseada em habilidades". Um modelo que impõe concepções dominantes de letramento a outros grupos sociais, mascarando as conjunturas culturais e ideológicas que o sustentam, apresentando-se de modo neutro e universal. Concordando com Street, o modelo autônomo “é, na verdade, profundamente 'ideológico' no sentido de que disfarça sua própria posição de poder e suas alegações, representando suas visões como se fossem independentes da cultura, universais, 'autônomas'" (STREET, 2013, p. 54).

Street (2012, p. 69-72) esclarece que surgiram vários termos referentes a letramento, especialmente ligados à concepção social da leitura e da escrita. Em meio aos termos que emergiram, o autor anuncia que ajudou a desenvolver a expressão múltiplos letramentos, que foi criada em oposição a se ter apenas um letramento dominante com "L" maiúsculo e "o" minúsculo, um letramento singular, autônomo e reificado. Contudo, Street observa que a expressão múltiplos letramentos pode incorrer também na reificação, na problemática de se ter um letramento único e alinhá-lo a uma cultura única, como se ter letramentos múltiplos associados, supostamente, a culturas múltiplas. 
Recentemente, como lembra Street, outro termo despontou com os autores do Novo Grupo de Londres que "apresentaram a noção de multiletramento em referência não a múltiplos letramentos, associados a culturas diferentes, mas a formas múltiplas de letramento associadas a canais ou modos, como o letramento do computador, o letramento visual" (STREET, 2012, p. 72-73). Trata-se de uma associação, em especial, relacionada a canais e modos de comunicação. É uma abordagem muito diferente de múltiplos letramentos, já que inclui inúmeras outras formas semióticas de comunicação além da leitura, da fala e da escrita. Mas possui o mesmo problema de incidir na reificação, como também no determinismo, e não levar em conta as práticas sociais em relação ao letramento no contexto, o que resultaria na manutenção de uma hegemonia. Desse modo, nosso desafio é olhar a língua ${ }^{3}$ como relacional, sociocultural, emergente e histórica.

Para tanto, agenciamos a reflexividade para a consciência crítica pelo modelo ideológico de letramento de Street (2013, p. 53-54).

O modelo alternativo, ideológico, de letramento oferece uma visão culturalmente mais sensível das práticas de letramento, pois elas variam de um contexto para outro. Este modelo parte de premissas diferentes daquelas do modelo autônomo - ele postula, ao contrário, que o letramento é uma prática social, e não simplesmente uma habilidade técnica e neutra; que está sempre incrustado em princípios epistemológicos socialmente construídos. O modelo diz respeito ao conhecimento: as formas como as pessoas se relacionam com a leitura e a escrita estão, elas mesmas, enraizadas em concepções de conhecimento, identidade, ser.

Souza (2017, tradução nossa), em seu estudo, referindo-se a Street e ao modelo ideológico que ele propõe, reconhece que para Street a leitura e a escrita vão além da alfabetização, de somente aprender o código, a relação fixada entre letra e som, pois entende que os conhecimentos da comunidade se fazem necessários para produzir e compreender os textos escritos, ou seja, o letramento é uma prática social que realmente considera os contextos de produção. Nessa ótica, refletimos sobre o ensino de língua inglesa que não deve ser somente para codificação e decodificação, um ensino "autônomo", mas com um letramento crítico, com uma abordagem ideológica na busca pelas origens do dizer, e uma tradução compreendida na relação empática entre os

\footnotetext{
${ }^{3}$ Abordamos a língua como emergente, relacional, social, cultural e histórica do modo como Lynn Mario T. Menezes de Souza proferiu em aula por videoconferência para o curso de pós-graduação em Estudos Linguísticos da Universidade Federal de Uberlândia, em maio de 2018.
}

Revista do SELL, Uberaba - V. 8 n. 2, p. 404-419, Jul./Dez. - 2019. 
contextos que envolvem a língua no processo de aprendizagem que afeta para a atitude solidária e com responsabilidade consigo e com o outro, individual e coletiva.

Articulamos esse modelo de letramento ideológico, os Estudos dos Novos Letramentos, à proposta do letramento crítico pela prática ideológica como uma ferramenta, que possa dizer, emancipatória ${ }^{4}$ no ensino de língua inglesa como língua estrangeira, que condiz com uma percepção do lugar de fala, da infusão da ideologia e das relações de poder desiguais que circulam pela língua e que podem emergir em sala de aula com o dissenso, como sugere Souza (2011b, p. 297), com um conflito para percepção e compreensão das diferenças. Trata-se da consciência crítica no aprendizado da língua inglesa para a prática social com ética e justiça, isto é, de conceber a existência de diferentes contextos e o respeito ao "eu" e ao "outro". Sobre a língua, lembrada por Kachru (1994, p. 291) como ferramenta de dominação, uma língua de poder, vale destacar a posição-nativo e não-nativo, de formações identitárias e de posicionar-se a partir do seu contexto e lugar de utilização da língua, de não renegar as origens do leitor, do autor, do falante, mas de negociar a interpretação e a tradução entendidas nos contextos. Isso implicaria o deslocamento dos discursos que circulam sobre a língua inglesa, mormente, por escolas de idiomas no Brasil que negociam, vendem 0 aprendizado da língua inglesa como se fosse a primeira língua do brasileiro. Este que vai se subjetivando nesses discursos pela língua-pátria do corpo inglês. Que se arrisca a outra identidade em prol de "ter vez" para fazer e dizer e de "ser" como o ideário de representação do sujeito-europeu que persiste na pós-colonização.

Nesse sentido, os estudos emergentes pós-coloniais, que tratam, dentre suas discussões, sobre relações de poder, de subalternidade, contribuem para dialogar com a proposta do letramento crítico, sociocultural, na linha de um modelo ideológico como indica Street (2013). Proposição que respeita as práticas de letramento conforme os contextos e mobiliza o conflito, o dissenso a favor da heterogeneidade da língua, dos sujeitos, em oposição à dominação, à homogeneização, ao universalismo que um processo educacional e um letramento escolar autônomo, um ensino focado em regras

\footnotetext{
${ }^{4}$ Emancipatória entendida aqui não no sentido de "levar" o outro a se emancipar, mas com uma perspectiva de desvencilhar de amarras de poder, do colonialismo que, por exemplo, pode fixar o sentido desejado na interpretação/tradução/ensino, que tende ao controle, à homogeneidade, ao automatismo. Emancipar compreendida como possibilidade de negociar, como condição de ser, escutar e perceber o outro com ética e respeito. Assumida, sobretudo, na esteira de Santos (2009, p. 24) na lógica da "racionalidade moralprática da ética e do direito", e com um fim para a transgressão empática.
}

Revista do SELL, Uberaba - V. 8 n. 2, p. 404-419, Jul./Dez. - 2019. 
fixas, invariáveis sócio-historicamente, em uma reprodução mecanizada como devolutiva sistemática de uma gravação, um tecnicismo ${ }^{5}$, uma tradução não trabalhando a língua como relacional/social, enfim determinações calcadas no eurocentrismo e em relações de saber-poder, como aponta Foucault (2004, p. 27), poderiam compactuar. Desse modo, a proposta do letramento crítico (no modelo ideológico) coaduna com o sentido empregado de decolonização, que, como indica Tiffin (1994, p. 95, tradução nossa), se trata de um processo, e não de chegada. Um processo dialético, pela hibridização cultural e a percepção das identidades pelo contra-discurso ${ }^{6}$, pela visão da hegemonia por esta mesma. E aqui também pela própria percepção dos considerados subalternos/culturas da periferia/terceiro mundo.

\section{Letramento crítico, ensino de língua inglesa e estudos emergentes decoloniais}

A aquisição da segunda língua, mesmo que não nos demos conta disso, acontece, como explica Revuz (1998, p. 215), por termos tido acesso antes à linguagem, à língua materna, que é tomada como referência para o aprendizado da língua estrangeira. Como expõe Revuz:

Se é verdade que aprender uma língua estrangeira é avançar, mesmo que modestamente, em relação aos discursos sociais e familiares que nos perseguem, nos constroem e nos coagem, e é afrontar um espaço silencioso no qual é preciso se inventar para dizer eu, então, aprender uma outra língua é fazer a experiência de seu próprio estranhamento no mesmo momento em que nos familiarizamos com o estranho da língua e da comunidade que a faz viver. Há muitas maneiras de eludir essa experiência, porém, não será sempre entregar-se a um duplo desconhecimento: desconhecimento do Outro, da alteridade e desconhecimento de si e do próprio estranhamento? (REVUZ, 1998, p. 228-229).

Relacionamos o aprendizado da segunda língua como Revuz pontua com a indicação do modelo ideológico de letramento, abarcado por Street (2013) como prática social, pensando na língua como relacional. Língua que compreende a língua materna (L1) para a aquisição da segunda língua (L2), e pressupõe uma hibridização, certo cruzamento, um

\footnotetext{
5 Pensado como uma valorização da técnica a favor da dominação. Como relaciona o modelo autônomo de Street (2013).

6 Os dizeres da literatura pós-colonial, mas pensado para além das estratégias anunciadas por Tiffin (1994, p.95-98, tradução nossa), como trabalho sobre a produção dos discursos coloniais e sobre transformações em meio a colônias.
}

Revista do SELL, Uberaba - V. 8 n. 2, p. 404-419, Jul./Dez. - 2019. 
"acordo" comportando o contexto dessa relação entre L1 e L2 no processo de ensino e aprendizagem. Acontecimento que não é neutro e que não deve ser puramente técnico, autônomo. Afinal, estamos diante da língua que é um fenômeno sociocultural, e que também não é neutra. Compreendemos o sujeito como um construto social, que nasce em uma comunidade que já possui valores, crenças, ideologia, língua, que vão construindo sua formação. Nesse sentido, o sujeito aprende a partir das identificações/interpelações que o constroem no convívio comunitário, em meio à ideologia que é anterior e concomitante a ele.

Ademais da língua dos sujeitos constituídos na diversidade da comunidade, pelas singularidades de cada membro da sua comunidade de origem, o contato facilitado entre diferentes línguas e culturas, que é efeito do fenômeno da globalização e do colonialismo, como esclarece Rajagopalan (2009), propicia o multilinguismo, a variação linguística pelas fusões e fundações. Daí, podemos dizer que proporciona também o conflito. E é sobre esse hibridismo que nos debruçamos ao entendermos o sujeito como híbrido em sua constituição social, comportando híbridos valores pela língua.

Nessa ótica, o contato com a língua estrangeira produz um hibridismo sociocultural, um entremeio que não deve ser tomado pelo jogo de forças de dominação, mas se valer da ética, da justiça social e da empatia cultural. E o letramento crítico é uma ferramenta que pode propor essa empatia. Pois, possibilita a consciência crítica do "eu" e o respeito ao "outro", como indicam Freire (2002) e Souza (2011a), ao entender que os sujeitos se formam, adquirem seus valores nas comunidades a que pertencem. Seus construtos sociais variam em conformidade com seus contextos. Desse modo, os sentidos que conferem às leituras, ao mundo, são lançados a partir do olhar constituído nas suas comunidades. Ressalta-se que os sentidos e os sujeitos se constituem em uma simultaneidade histórico-ideológica. A sala de aula de língua inglesa é um exímio exemplo de lugar de diversidades, de múltiplos sujeitos, alunos e professor, autores e atores dos materiais didáticos que comunicam apoiados em seus contextos socioideológicos. É um espaço de possibilidades de construção de sentidos plurais. Textos e vídeos da cultura inglesa que adentram a sala de aula em atividades para aquisição da escrita e da oralidade na língua inglesa, bem como os métodos e procedimentos pedagógicos do professor e da instituição de ensino comportam os contextos de produção, situação, como também as relações de saber-poder que subjazem, e são mecanismos de subjetividades. 
Para tanto, a empatia no ensino se traduz na mediação, no entendimento relacional das línguas e culturas/contextos, ou seja, na mediação reflexiva que os sentidos das palavras, dos textos carregam a partir da constituição e visão de "dois" sujeitos, sujeito-leitor e sujeito-autor; falante e ouvinte, logo das percepções de dois contextos, o de produção e o de interpretação, que em dada instância possibilitam se entrecruzar e oportunizam o diálogo. Como aduzem Kubota e Miller (2017, p. 22, tradução nossa) "A práxis deve ser exercida com humildade e sensibilidade contextual". É nessa vertente que se visualiza o letramento crítico no ensino de língua inglesa, em relação à prática docente e metodologias de ensino e, especialmente, para a tradução, já que uma afirmação em um contexto pode ter um significado muito diferente do que teria em outro.

\begin{abstract}
Numa perspectiva de letramento crítico, que valoriza a diferença de história, de origem, de lugar de cada intérprete social, [...] envolver o participante no processo conflitante e doloroso do confronto entre interpretações e valores diferentes. Precisamos educar para a diferença, preparar para o conflito, se não a gente vai entender que toda vez que surge uma diferença ela precisa ser eliminada. $O$ educando deve perceber as consequências que suas interpretações e valores podem ter sobre o outro, que ele e o outro possuem interpretações e valores diferentes: essa é a dimensão ética. (SOUZA, 2011b, p. 298).
\end{abstract}

A prática do letramento crítico, a abordagem ideológica, torna-se necessária, principalmente hoje, no mundo globalizado, em que circula uma gama de informações e ainda difundem discursos acerca da primazia econômica, sociocultural, de conhecimentos de países ingleses, em específico o estadunidense. Isto pela supremacia homogeneizante de poder e conquista conferida, particularmente, pela colonialidade, que cria no imaginário do colono o ideal sociocultural de melhores povos e língua. Incluímos aqui o que aduz Jordão (2010, p. 429) sobre a língua inglesa no mundo hoje poder ser posta como commodity, como um produto em massa que é comprado e vendido por "teias" discursivas que subjetivam na ilusão de que sua mera aquisição é a garantia de ascensão social.

Posto isto, o letramento crítico funciona então como uma ferramenta, dentre outras, que oportuniza o "enfrentamento" crítico-reflexivo do imperialismo cultural, da superinfluência geopolítica de um país sobre o outro. Uma ferramenta de poder emancipatótria pensada em relação ao grande projeto de descolonização apresentado por Mignolo (2010) em seus estudos, um modo de romper com uma monocultura do pensamento. Um pensar "único" que se relaciona com a visão de Souza (2017) sobre 
imputarem uma homogeneidade da língua. Mas, como lembra Souza (2017, tradução nossa), "a heterogeneidade antecede a homogeneidade da língua". Uma proposta para o entendimento do contra-discurso colonial, de modo que "as diferenças podem se relacionar com o mesmo" (SOUZA, 2014, p. 53-54, tradução nossa), ou seja, com a língua "relacional", um diálogo intercultural e mudança da lógica de domínio e de visualização para uma cultura, somente. A reprogramação de distorções que culminaram na projeção, por outros países, das experiências e pensamentos de países como os de "primeiro mundo". Em um "depósito" que ocorre pela sobredeterminação eurocêntrica de um saberpoder de produção que subjetiva os outros do mundo. Isso para nós marcadamente no ensino em que se nota 0 acesso demasiado à literatura científica e às produções artísticas desses "grandes" países, com o dizer de que são os melhores, únicos assim, melhores autores, filmes, sem dimensionarem questões sócio-históricas e econômicas.

Nessa perspectiva, engaja-se a formação na língua inglesa com base em uma educação para a transgressão responsável como propõe Pennycook (2006). Uma prática de ensino transgressora de modo que não se filia à colonialidade, e às desigualdades de poder instituídas pela língua. Pensamos, então, uma educação a partir de políticas e planos que transgridam o modelo eurocêntrico infiltrado desde o ensino tradicional à educação na modernidade. Um ensino que não pactua com a indiferença, mas com o respeito ao outro e concebe 0 aprendizado da língua sob a reflexividade ${ }^{7}$ desafiadora para a transformação social, para a consciência crítica de si e, portanto, a compreensão respeitosa ao "eu" e ao "outro". Processo de ensino-aprendizagem que, como indica Freire (2002, p. 17), trabalha para a disponibilidade em aceitar o novo, e rejeita quaisquer formas de discriminação. Não assegura o universalismo que pressupõe a dominação e não apaga as histórias em que as línguas de origem dos falantes aspirantes à língua estrangeira estão inseridas. Assim, a língua não é ensinada e aprendida como imposição, empoderamento ou promoção de uma cultura logocêntrica, não é um marketing mercadológico, ou um fator de exclusão, mas sim como processo de afeição e empatia, uma experiência de hibridismo reflexiva, de tradução empática, para a criticidade, como sinalizada por Tagata (2017, p. 390), em que se assume a responsabilidade pelos

\footnotetext{
7 Pensada como consciência entre os sujeitos, empatia e convívio com a diferença, com respeito às diferentes histórias e posições econômicas, sociais e políticas.
} 
sentidos que atribuímos, concorrendo para a participação social e a relação ou o convívio intercultural.

\begin{abstract}
Uma proposta de ensino de língua inglesa pautada no desenvolvimento dessa autorreflexividade crítica pode estimular um pensamento inventivo e prospectivo, tirando-nos da zona de conforto de nossas velhas referências linguísticas e culturais, e levando-nos a sondar até onde podem ir as singularidades de outras línguas e culturas, e como essas singularidades nos forçam a rever nossas categorias de pensamento - atitudes que considero éticas. (TAGATA, 2017, p. 402).
\end{abstract}

Trata-se de um processo de ensino e aprendizagem pautado na ética e no respeito a si e ao outro, a uma percepção de como estamos, como aponta Souza, (2011b, p.298), "impicados" com o outro.

O importante é perceber como cada eu está implicado no outro, [...], conectado com o outro, estar atento ao fato de que as necessidades e valores do outro se conectam às nossas e vice-versa; nossas interpretações dos outros têm consequências sobre a vida do outro, e vice e versa, daí a nossa implicação, a nossa responsabilidade perante o outro e vice-versa. (SOUZA, 2011b, p. 298-299).

O ensino da língua inglesa com o letramento crítico nessa vertente contribui com a questão que Revuz (1998, 228-229) apresenta em relação ao "estranhamento", ao "duplo desconhecimento: de si e do outro" na aquisição da língua estrangeira. Nessa direção, o aprendizado da língua estrangeira não se vincula a uma prática discursivo-pedagógica de "dor", ou um sentimento "doloroso", na aquisição da outra língua, e nem a um ato de violência ao outro, a uma cultura, pois o letramento crítico possibilita a habilidade de refletir e compreender que os sujeitos, as línguas e os contextos são diferentes, estão no curso da história. Esse entendimento pode contribuir para elidir o desejo hoje de dominar, excluir ou anular o outro, revendo o sentido da palavra "humanidade". Estaríamos diante de um redimensionamento da prática educativa e dos discursos que ressoam ao longo dos anos de formar o aluno: "um cidadão crítico e participativo", "um cidadão crítico e consciente". A habilidade na leitura de um texto de língua inglesa de "ouvir" o outro (autor), de refletir sobre si (leitor) e os diferentes contextos, e de mediar uma compreensão empática pela criticidade pode agenciar, relacionando com o conceito de agência segundo Jordão (2010, p. 432), "uma forma de intervir no processo discursivo de 
construção de sentidos e representações do mundo", afirmando esse discurso pedagógico.

Destarte, consideramos a prática do letramento crítico, ideológico, pelo viés freireano da ação-reflexão, com a reflexividade pela escuta do "outro", para a tomada de posição empática e "emanciação", consciência crítica no ensino e na aprendizagem da língua inglesa, contribuindo então para o diálogo intercultural para e pela língua relacional, democrática e ética, ou seja, para transformações da prática de ensino para a prática da vida crítica e reflexiva.

\section{CONSIDERAÇÕES FINAIS}

Neste trabalho, defendemos a prática de ensino de língua inglesa com o letramento crítico na perspectiva do modelo ideológico de Street (2013), em oposição ao que o autor conceitua como modelo autônomo. É notório que o ensino de língua inglesa necessita de desvencilhar de amarras coloniais com tradições de ensino com práticas de repetição e memorização, de perpetuação das histórias dos colonizadores, isto é, dos modelos que os dominadores querem que sejam seguidos. Então, de enfoque em regras rígidas/fixas, no grafocentrismo, e que se imbricam à lógica tanto do modelo eurocêntrico enaltecedor da cultura inglesa, quanto do modelo autônomo de letramento que se relaciona diretamente à ordem de poder dessa cultura.

Portanto, aliamos o letramento crítico aos estudos emergentes pós-coloniais para refletirmos sobre as práticas de ensino atuais, e sugerimos o letramento crítico, ideológico, na prática de ensino da língua inglesa com esses estudos através do dissenso, do conflito como explica Souza (2011b, p. 297) para a reflexividade e para a habilidade de convívio com as diferenças. Nessa linha, entendemos a tradução como relacional empática, pela compreensão do contexto do leitor e do autor, o que favorece um aprendizado menos "forçado" ou "agressivo" para o aluno. O letramento crítico pode contribuir então para o desenvolvimento de habilidades outras, para além da prática oral e escrita mecânica e normatizada, como aflorar sentidos, e então sujeitos, para a criticidade, a empatia, a ética, o diálogo intercultural mais horizontalizado, sobretudo no ensino da língua inglesa, na lida direta com uma cultura posta como dominante. Habilidades estas que pensamos constituírem os fundamentos humanos e 
socioeducativos, a razão emancipatória entendida como a consciência crítica e o respeito a si e ao outro, como indica Freire (2002).

O letramento crítico no ensino da língua inglesa nessa concepção pode transgredir o "olhar de cima", o eurocentrismo, afinal, favorece a consciência crítica, considera as habilidades existentes nos variados contextos, nos sujeitos, como as da língua materna, e rejeita o pensamento dominante de progresso em uma única direção, pois preza pelo diálogo intercultural. O letramento crítico pode ser eleito como ferramenta de poder emancipatório não com forças de formação para o confronto "armado", a revolta, a violência, mas como política curricular e pedagógica para se pensar uma revolução paradigmática em relação a uma mudança de um tempo de subalternidades, de práticas concêntricas, para um tempo de vivência harmoniosa pelo respeito às diferenças, de diálogo intra e intercultural de base equânime, uma política socioeducativa que desenha uma nova história de possibilidades para o exercício da cidadania, a prática da democracia e a justiça social.

\section{REFERÊNCIAS}

FOUCAULT, M. Vigiar e Punir: nascimento da prisão. Tradução de Raquel. 29 ed. Petrópolis: Vozes, 2004.

FREIRE, P. Pedagogia da Autonomia: saberes necessários à prática educativa. 25 ed. São Paulo: Paz e Terra, 2002.

GOULART, C. M. A. O conceito de letramento em questão: por uma perspectiva discursiva da alfabetização. In: Bakhtiniana, São Paulo, v. 9, n. 2, 2014. p. 35-51.

HALL, Stuart. Quem precisa de identidade? In: SILVA, Tomaz Tadeu da. (org.), HALL, Stuart; WOODWARD, Kathryn. Identidade e diferença: a perspectiva dos estudos culturais. 8. ed. Petrópolis, RJ: Vozes, 2008. p. 103-133.

JORDÃO, C. M. A posição de professor de inglês no Brasil: hibridismo, identidade e agência. Revista. Letras \& Letras, Uberlândia, v.26, n.2, 2010. p. 427-442.

JORDÃO, C. M.; MARTINEZ, J. Z. Entre as aspas das fronteiras: internacionalização como prática agonística. In: ROCHA, C. H.; BRAGA, D. B.; CALDAS, R. R. (Orgs.) Políticas Linguísticas, ensino de línguas e formação docente. Campinas: Pontes, 2015. p. 61-87.

KACHRU, B. B. The Alchemy of English. In: ASHCROFT, B.; GRIFFITHS, G.; TIFFIN, H. The post-colonial studies reader. London and New York: Routledge, 1994. p. 291-295.

KUBOTA; R.; MILLER, E. R. Re-Examining and Re-Envisioning Criticality in Language Studies: Theories and Praxis, Critical Inquiry in Language Studies. In: Critical Inquiry in Language Studies, $0: 1-29,2017$. 
MIGNOLO, Walter. Desobediência epistémica: retórica de la modernidad, lógica de la colonialidad, y gramática de La descolonialidad.Buenos Aires: Ediciones del signo, 2010.

MIGNOLO, Walter. A colonialidade de cabo a rabo: o hemisfério ocidental no horizonte conceitual da modernidade. In: Lander Edgardo (org.). A colonialidade do saber: eurocentrismo e ciências sociais. Perspectivas latino-americanas. Buenos Aires: CLACSO, 2005. p. 33-49. Disponível em: <https://edisciplinas.usp.br/pluginfile.php/2591382/mod_resource/content/1/colonialidade_do_sabe r_eurocentrismo_ciencias_sociais.pdf >. Acesso em: 07 jul. 2019.

PENNYCOOK, A. Uma linguística aplicada transgressiva. In: MOITA LOPES, L. P. (Org.) Por uma linguística aplicada INdisciplinar. São Paulo: Parábola Editorial, 2006. p. 67-84.

RAJAGOPALAN, K. Exposing young children to english as a foreign language: the emerging role of world English. Trabalhos em linguística Aplicada. (online) v.48, n. 2, Campinas, 2009. Disponível em: <http://www.scielo.br/scielo.php?script=sci_arttext\&pid=S0103$18132009000200002>$. Acesso em: 10 jun. 2019.

REVUZ, C. A língua estrangeira entre o desejo de um outro lugar e o risco do exílio. In: SIGNORINI, I. (Org.). Língua(gem) e Identidade: elementos de uma discussão no campo aplicado. Campinas: Mercado das Letras; São Paulo: Fapesp, 1998. p. 213-230.

SANTOS, Boaventura de Sousa (2009). Para além do pensamento abissal: das linhas globais a uma ecologia de saberes. In: SANTOS, B. S.; MENESES, M. P. (orgs.). Epistemologias do Sul. Coimbra: Almedina, p. 23-71.

SOUZA, L. M. T. M. Multiliteracies and transcultural education. In: García, O., Flores, N. and Spotti, M. Handbook of Language and Society. Oxford Handbooks Online.2017.

SOUZA, L. M. T. M. Epistemic Diversity, Lazy Reason and Ethical Translation in Post-Colonial Contexts: the case of indigenous educational policy in Brazil. Interfaces Brasil/Canadá. Canoas, v. 14, n. 2, 2014. p. 36-60.

SOUZA, L. M. T. M. Para uma redefinição de Letramento Crítico: conflito e produção de significado. In: MACIEL, Ruberval Franco; ARAÚJO, Vanessa de Assis (Org.). Formação de professores de línguas: ampliando perspectivas. Jundiaí: Paco Editorial, 2011a. p. 128-140.

SOUZA, L. M. T. M. O professor de inglês e os letramentos no século XXI: métodos ou ética? In: JORDÃO, C. M.; MARTINEZ, J. Z.; HALU, R. C. (Org.). Formação “desformatada”: práticas com professores de língua inglesa. Campinas: Pontes Editores, 2011b. p. 279-303.

STREET, B. V. Políticas e Práticas de Letramento na Inglaterra: uma perspectiva de letramentos sociais como base para uma comparação com o Brasil. In: Cad. Cedes, Campinas, v. 33, n. 89, jan.-abr. 2013. p. 51-71.

STREET, B. V. Eventos de letramento e práticas de letramento: teoria e prática nos novos estudos do letramento. In: MAGALHÃES, I. Discursos e práticas de letramento: pesquisa etnográfica e formação de professores. Campinas, SP: Mercado das Letras, 2012. p. 69-92.

TAGATA, W. M. Letramento crítico, ética e ensino de língua inglesa no século XXI: por um diálogo entre culturas. RBLA, Belo Horizonte, v. 17, n.3, p. 379-403, 2017. Disponível em: <http://dx.doi.org/10.1590/1984-6398201710973>. Acesso em 08 abr. 2019. 
SANTOS, F.O.

TIFFIN, Helen. Post-colonial Literatures and Counter-discourse. In: ASHCROFT, B.; GRIFFITHS, G.; TIFFIN, H. The post-colonial studies reader. London and New York: Routledge, 1994. p. 95-98.

Como citar este artigo (ABNT)

SANTOS, F.O. Letramento crítico no ensino de língua inglesa: uma ferramenta de poder emancipatória. SELL, Uberaba, MG, v. X, n. X, p. XXX-XXX, 2019. Disponível em: <inserir link de acesso>. Acesso em: inserir dia, mês e ano de acesso. DOI: inserir link do DOI.

Como citar este artigo (APA)

SANTOS, F.O.(2019). Letramento crítico no ensino de língua inglesa: uma ferramenta de poder emancipatória. SELL, $\mathrm{X}(\mathrm{X}), \mathrm{XXX}-\mathrm{XXX}$. Recuperado em: inserir dia, mês e ano de acesso de inserir link de acesso. DOI: inserir link do DOI. 